\title{
Corporate and Grassroot Frugal Innovation: A Comparison of Top-Down and Bottom-Up Strategies
}

\author{
Liza Wohlfart, Mark Bünger, Claus Lang-Koetz, and Frank Wagner
}

\author{
(6 There's no such thing as simple. Simple is hard. ") \\ Martin Scorsese \\ Film director and producer
}

\begin{abstract}
Frugal innovations aim at the development of basic solutions that are affordable for pricesensitive customer groups. This article looks at the similarities and differences between two major approaches, corporate and grassroot frugal innovation, and identifies initial ideas on how the two streams can learn from each other. The three pillars of sustainability (economic, environmental, and social) provide one of the guidelines for the comparison. The research is based on an analysis of case studies from various industries, six of which are presented in this article.
\end{abstract}

\section{Introduction}

Frugal (i.e., simple, plain) innovations restrict products and services to basic functionalities and embed them in innovative business models to make them affordable for price-sensitive customer groups. Frugal innovation is usually associated with emerging countries such as the BRICS (Brazil, Russia, India, China, and South Africa). It is, however, not a new phenomenon and is not restricted to specific geographical regions. Europe and North America, for example, also offer interesting examples of frugal innovation. They range from innovative concepts of large companies to bottom-up initiatives and aim both at emerging countries and their home markets.

Some companies and universities have even started to establish a dedicated infrastructure for developing frugal innovations. Santa Clara University in Silicon Valley - one of the wealthiest regions in the world - has a Frugal Innovation Lab in its engineering department. Its goal is to develop solutions for people with limited economic resources, whether they are African farmers, children with disabilities requiring expensive support, citizen scientists and students, or homeless people in American cities. The constraints of the lab (e.g., tools and materials) help students as part of their engineer- ing curriculum, not only solving ecological or social sustainability needs, but also making them into better, more creative engineers.

Also in Silicon Valley, there is a strong new trend in technology product development: the lean startup and the minimum viable product (MVP). Even startups that have millions of dollars of venture funding are encouraged to follow this frugal approach to design and engineering, not because it is more sustainable, but simply because it is more effective at creating new products.

Frugal innovation has been a topic in academic and industrial discussions for several years now. Many authors have highlighted the large variety of names for the phenomenon, such as inclusive, grassroot, resourceconstrained, or cost innovation (Zeschky et al., 2011). Few researchers have, however, compared and contrasted the different activities to identify the core of the frugal innovation phenomenon or to clearly separate the different streams.

One common aspect of all frugal innovations is their link to sustainability. Frugal innovations are characterized (almost by definition) by a lack of resources, either in the development process or the solution itself. They can, however, contribute to all three pillars of sustain- 


\title{
Corporate and Grassroot Frugal Innovation
}

\author{
Liza Wohlfart, Mark Bünger, Claus Lang-Koetz, and Frank Wagner
}

ability. Frugal innovations can be very profitable from an economic point of view. They can support environmental aims by saving material and energy. And they can have social benefits by making products affordable for more people or creating new work places. Frugal innovation could thus be a strong impetus for sustainability that has not yet been leveraged to a full extent.

This article contrasts two innovation approaches, topdown ("corporate frugal") and bottom-up ("grassroot frugal"). The three pillars of sustainability provide one of the key guidelines for this comparison. Relevant research questions considered are the following:

- What are the key differences and similarities between corporate and grassroot frugal innovation approaches?

- How important are the different aspects of sustainability (economic, environmental, social) in both approaches and how can they be operationalized?

-What can the two streams learn from each other?

The research presented in this article has been conducted by researchers from three different organizations, who have specialized on different aspects of the frugal phenomenon. Organization A (name anonymized) focuses on corporate frugal solutions, Organization B (name anonymized) specifically looks into grassroot frugal phenomena, and Organization C (name anonymized) investigates sustainability aspects of frugal innovations.

The research questions above have been addressed by an extensive literature review followed by a large number of case studies, which have been collected in recent years to identify characteristics and success factors of as well as methods and tools for frugal innovation.

\section{Corporate Frugal: Top-Down Solution Trimming}

Large companies have started to pay a lot of attention to frugal business opportunities, since Prahalad raised awareness in his book The Fortune at the Bottom of the Pyramid (2010). The striking idea is that companies offering frugal innovations can at the same time make profit from affordable high-quality solutions and contribute to better living conditions of the less well-off.

Corporate frugal examples include the Volkswagen Beetle and IKEA. The original Volkswagen Beetle not only became enormously popular because young people could afford it; it was also praised for its robustness and extravagant design. IKEA likewise has set a clear focus on the needs of its key target group: young families. The company's strong and growing success results from a careful balance of low price, modern aesthetics, and services for small children.

The strict orientation on the specific needs of a selected customer group is a typical feature of Western companies venturing into frugal innovation. They identify a specific group of potential cost-sensitive customers, carefully analyze their needs, and then make clear-cut decisions on relevant features from these customers' perspective to bring down prices. They compromise on the solution spectrum, not on quality, when aiming for affordability. And they even add features that bring up the price if they have a strong relevance for the specific target group. The result is a good-quality solution that is cheaper than existing high-end offerings but more expensive than established low-end alternatives.

The development of corporate frugal solutions is not an easy task because it necessitates a shift of mind-set in established $R \& D$ teams: from the design of sophisticated high-end products to a philosophy of reduction. At the same time, frugal solutions have to mirror the quality of the overall company brand to avoid an endangerment of existing product lines.

The development process of corporate frugal innovations is therefore usually not less complex than the one of high-end innovations. Companies use a structured procedure and established methods to come up with frugal innovations. The costs of the invested resources can even exceed the ones of other innovation projects; some companies stressed that the radical re-thinking of frugal innovation needs the vast expertise of specifically skilled senior staff. This staff usually works in dedicated $\mathrm{R} \& \mathrm{D}$ teams that closely collaborate with customers to make sure that their needs are well understood.

Market opportunities that promise economic success are the main driver for the development of corporate frugal solutions. They have smaller margins than highend products but can still be very profitable due to economies of scale achieved through mass-manufacturing. Corporate frugal solutions that primarily aim at environmental and social sustainability in turn often seem to fail, as seen with the BSH Protos Plant Oil Cooker and the Nike World Shoe project. The specifics of corporate frugal highlighted so far are presented more explicitly in three detailed case studies presented below. 


\section{Corporate and Grassroot Frugal Innovation}

\section{Liza Wohlfart, Mark Bünger, Claus Lang-Koetz, and Frank Wagner}

\section{Case study 1: Mettler Toledo Entry line}

Mettler Toledo, a provider of high-end solutions, was increasingly attacked by low-cost competitors, whose solutions have a low quality but also a low price and are thus affordable for many companies in emerging countries (Strotz, 2014). As a consequence, Mettler Toledo decided to develop an entry-level product line with fewer features and a simpler design than the established Excellence and Classic lines (Figure 1; Table 1). Despite the differences, the three lines show clear similarities when it comes to style and quality. The frugal line clearly matches the overall brand image.

The development of the corporate frugal line was done in four steps (Strotz, 2014). Mettler Toledo first created Strategic Business Units with clear objectives (i.e., dedicated $R \& D$ teams) and strategies to then set up a product portfolio that considered the customers' will-
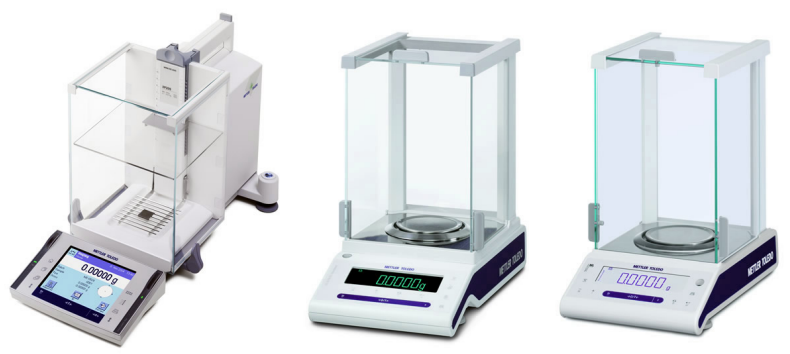

Figure 1. Mettler Toledo Excellence, Classic, and Entry laboratory balances

Source: Mettler Toledo ingness to pay and the benchmark on the market. Based on defined target costs, Mettler Toledo next established low-cost sourcing capabilities and developed a new sales approach (Strotz, 2014).

\section{Case study 2: Accor Ibis Budget hotel chain}

Accor is a hotel chain with a portfolio that encompasses luxury and upscale brands as well as midscale and economy ones. Its low-end hotel Ibis Budget (Figure 2; Table 2) started as Formule 1 in the 1980s, an affordable accommodation for travelling salespeople (Fraunhofer IAO, 2012).

The impulse to start the budget hotel chain was a clear market opportunity: the lack of a suitable solution for the target group. Travelling salespeople have a limited budget and specific requirements such as easy access to the hotel even at late hours and a room setup that ensures an optimum rest. The low price of the hotels was achieved by a strict focus on the key requirements of this customer group (Fraunhofer IAO, 2012). The hotels were placed at traffic junctions and offered simple but good quality furnishings. Services of less importance for salespeople were replaced by low-cost alternatives, including a 24-hours check-in machine instead of a personal receptionist.

In addition, costs were saved through a standardization of rooms, which enabled the industrialized production of furnishings, fast cleaning and maintenance processes, and quality assurance (Fraunhofer IAO, 2012).

Table 1. Case summary: Mettler Toledo Entry line

\begin{tabular}{ll}
\hline Dimension & Description \\
\hline $\begin{array}{l}\text { Novel product/service offering } \\
\text { (including target group) }\end{array}$ & $\bullet$ Entry-level laboratory balances aimed at Chinese low-end markets
\end{tabular}

Conventional offering with higher complexity (including target group)

- Excellence and Classic laboratory balances aimed at global high-end and medium markets
Approach for reducing complexity compared to conventional offering
- Copy \& paste, collaboration of central and local teams

Economic aspects

- Increasing market share in emerging markets

Environmental aspects

- Less material use (assumed)

Social aspects

- Provision of affordable quality solutions for companies with a low budget 


\section{Corporate and Grassroot Frugal Innovation}

\section{Liza Wohlfart, Mark Bünger, Claus Lang-Koetz, and Frank Wagner}

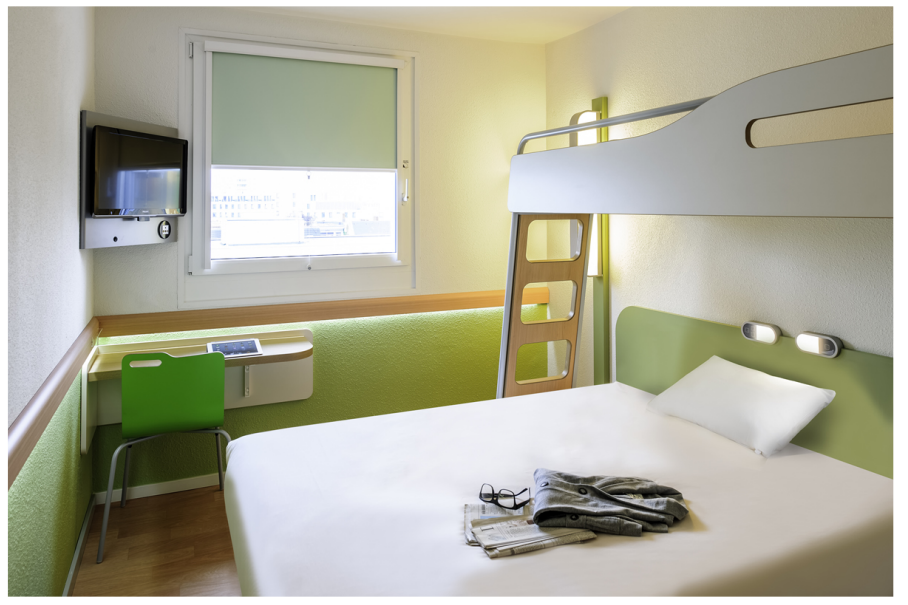

Figure 2. Accor Ibis Budget hotel room

Source: AccorHotels; Photographer: Christoph Weiss

Today, Ibis Budget is still in line with the original concept, although the room concepts have been modernized (Grallert, 2014). Many hotels still have restricted receptionist hours, supported by an automated check-in option. The emergence of competitors such as Motel One shows the high need for affordable accommodation. The different brands of Accor sometimes cannibalize each other, when customers change from a high-price to a low-price hotel, for example during times of economic crisis. However, this cannibalization can also be an advantage. Accor manages to keep customers attached to their portfolio in these situations, instead of losing them to competitors.
Case study 3: Siemens SMART line (healthcare sector) Siemens started its SMART (Simple, Maintenancefriendly, Affordable, Reliable, and Timely-to-market) line to explore new growth options (Fraunhofer IAO, 2014). In addition, they saw that competitors were very active in emerging countries and that the market shares of companies from these countries (i.e., "emerging giants") were growing. The SMART line extends Siemens' product portfolio from top- and high- to medium- and low-end markets and is a good fit to the global portfolio despite its differences in functionalities and price.

SMART line products can be found, for example in Siemens' healthcare sector offerings (Table 3). Medical SMART products have comparatively low prices (for both purchase and maintenance), good quality, and simple handling. Their affordability makes them attractive for healthcare professionals in emerging countries, who want to improve the ease and quality of their services. In addition, they sometimes serve as secondary or replacement device for professionals in developed countries (Fraunhofer IAO, 2014).

The development of the SMART healthcare products follows a structured process (Glemser, 2013). It starts with the identification of a target market and the analysis of the needs of this market as well as trends supported by local partners. The development and management of the products is then done by a local $R \& D$ team that knows about the specific requirements of the customers in this market and the features of com-

Table 2. Case summary: Accor Ibis Budget hotel room

Dimension Description

Novel product/service offering (including target group)
- Frugal hotel chain aimed at low-budget business travellers

Conventional offering with higher complexity (including target group)

- Luxury, upscale, and midscale brands aimed at high-budget business travellers and tourists
Approach for reducing complexity
compared to conventional offering

Economic aspects

Environmental aspects

Social aspects

- Standardization, automation

- $51 \%$ of Accor's operating result is from its economy segment (Grallert, 2014). 


\title{
Corporate and Grassroot Frugal Innovation
}

\author{
Liza Wohlfart, Mark Bünger, Claus Lang-Koetz, and Frank Wagner
}

Table 3. Case summary: Siemens SMART line (healthcare sector)

\begin{tabular}{|c|c|}
\hline Dimension & Description \\
\hline $\begin{array}{l}\text { Novel product/service offering } \\
\text { (including target group) }\end{array}$ & - Siemens SMART line aimed at medium- and low-end markets \\
\hline $\begin{array}{l}\text { Conventional offering with higher } \\
\text { complexity (including target group) }\end{array}$ & - Siemens SMART line aimed at top- and high-end markets \\
\hline $\begin{array}{l}\text { Approach for reducing complexity } \\
\text { compared to conventional offering }\end{array}$ & - Less functionalities, smaller size (exemplary) \\
\hline Economic aspects & $\begin{array}{l}\text { - The entry level in emerging countries offers a high potential sales volume and a } \\
\text { resulting high growth potential for Siemens (Glemser, 2013) }\end{array}$ \\
\hline Environmental aspects & - Low energy consumption (exemplary) \\
\hline Social aspects & $\begin{array}{l}\text { - Affordable (i.e., low price, low installation and operation costs) quality solutions for } \\
\text { budget-restricted hospitals and physicians }\end{array}$ \\
\hline
\end{tabular}

peting offerings. The team is supported by headquarter teams of the respective sector that can provide technical and procedural know-how. If possible, the complete value chain is also set up locally.

The development of the frugal solution is based on an existing product first, before a new solution is set up (Glemser, 2013). Costs are saved by optimizing the functionality spectrum, using inexpensive material and integrating components from local suppliers. A "mix and match" approach using existing components helps to reduce development costs. The two-step approach enables an alignment of the choice of functionalities with the market needs and to assess the product's chances of success. In addition, it helps to learn about the handling of the product technology and the translation of local requirements into product functionalities.

\section{Grassroot Frugal: Bottom-Up Solution Exploration}

Frugal innovation examples in developing economies often illustrate how people reuse materials and parts to which they have easy, free access, and how they apply clever shortcuts and workarounds to compensate for a lack of professional tools or skills. These practices occur in developed economies as well, but the materials, skills, and goals are very different. One could regard bil- lionaire Elon Musk's private spaceflight company SpaceX as an extreme example of frugal innovation, given that even a billionaire is a poor man compared to the superpower government space programs that previously had a monopoly on space technology. Who is resource-rich and who is resource-constrained is a relative assessment.

More down to earth examples of frugal innovation in developed economies, solving high-tech problems with relatively constrained resources, can be found in the maker movement and its adjacent cultures and organizations such as FabLabs and DIY (do it yourself) prosumers (producer/consumers). Here, we see individuals, companies, and communities hacking manufacturing supply chains, repurposing electronic devices, and even building entire cities using the principles of frugal innovation. Their accomplishments can be instructive for global corporations and developing economies alike.

Examples of frugal innovation in the developed world include:

- Briago braille printer (braigolabs.com). Young inventor Shubham Banerjee used the Lego Mindstorms EV3 kit (\$349) and a few parts from a hardware store to create a Braille printer that costs just $\$ 350$ (compared to $\$ 2000$ for a conventional machine). 


\section{Corporate and Grassroot Frugal Innovation}

\section{Liza Wohlfart, Mark Bünger, Claus Lang-Koetz, and Frank Wagner}

- BrickPi Bookreader (tinyurl.com/zgrtpkm). Invented by John Cole, the BrickPi opens and scans the pages of physical books in order to ensure that even old and rare books will be preserved and accessible. His digitizer uses the $\$ 30$ Raspberry Pi computer, and overall costs $\$ 450$ compared to $\$ 16000$ for conventional equipment.

- Foldscope (foldscope.com). Foldscope is a 2,000X magnification optical microscope that can be printed, cut, and assembled from a flat sheet of paper - for less than $\$ 1$.

In this section, we examine three innovations that use frugal principles of design and engineering to change products and processes normally found in developed economies. In each of the cases, the goals are environmental, social, or economic to various degrees, but each case has used ingenious ways to address the challenges of limited resources and turn them into an advantage.
Case study 4: Local Motors microfactory

The Rally Fighter by Local Motors' is a high performance sportscar (Figure 3). But, more important than the product, is how it was designed and manufactured. Local Motors' microfactory in Phoenix, Arizona, is home to an open source, crowd-powered manufacturing startup that took a new vehicle from concept to production in 18 months (vs 60 months for a typical carmaker) and cost about $\$ 3$ million to develop (vs $\$ 1$ billion for a traditional carmaker) (Table 4).

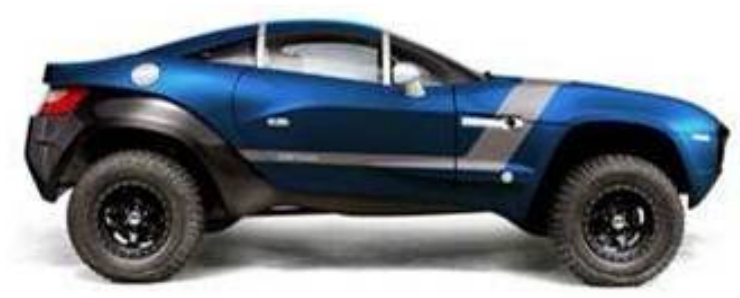

Figure 3. Local Motors Rally Fighter sportscar Source: Local Motors

Table 4. Case summary: Local Motors microfactory

\begin{tabular}{ll}
\hline Dimension & Description \\
\hline $\begin{array}{l}\text { Novel product/service offering } \\
\text { (including target group) }\end{array}$ & $\begin{array}{l}\text { High performance sportscar with high degree of customizability and flexible } \\
\text { manufacturing }\end{array}$ \\
\hline $\begin{array}{l}\text { Conventional offering with higher } \\
\text { complexity (including target } \\
\text { group) }\end{array}$ & $-\begin{array}{l}\text { BMW5 series, Audi, Mercedes, and other performance sportscars produced in } \\
\text { traditional cost-intensive manufacturing process }\end{array}$ \\
\hline
\end{tabular}

Approach for reducing complexity compared to conventional offering

Economic aspects
- Open source design, reuse of existing parts and supply chain, owner participation, and manufacturing space frame architecture

- $3 D$ printed car reduces part count and assembly steps, while offering vastly greater design flexibility

- Cost of car itself is comparable to other sportscars $(\$ 100 \mathrm{k})$, but cost of manufacturing (factory, tools, designs) are about $1000 x$ lower and 3-5x faster than conventional

- Produced Rally Fighter in 18 months (vs 60 for OEM) with 50 full-time employees

- $\$ 3$ million on development (vs $\$ 1$ billion for conventional)

- Breaks even at 2,000 units total (compared to 20,000/year for conventional)

Environmental aspects

- Local manufacturing reduces transportation distance, thus reducing emissions and infrastructure from logistics

- Prints vinyl skin exterior design - no paint shop, and each car is unique

Social aspects

- Microfactories return manufacturing jobs to local communities. Workers enjoy responsibility for end-to-end processes, and variation in tasks and products expands their skills and motivation 


\section{Corporate and Grassroot Frugal Innovation}

\section{Liza Wohlfart, Mark Bünger, Claus Lang-Koetz, and Frank Wagner}

Local Motors currently has four microfactories in Phoenix, Las Vegas, Louisville, KY, and Berlin. Each requires about $\$ 500,000$ in capital equipment and is open as a makerspace "lab" to local schools and inventors. The company aims to have 50 microfactories globally within 5 years, one million participants in its communities, and 1,000 products (not just cars) for sale. It has partnerships with companies such as GE to apply the process to home appliances (see firstbuild.com). Like the "just-in-time" approach from a generation ago, the new, frugal approach to manufacturing could change the way supply chains are planned and how factories are staffed - favouring smaller, local workshops that can profitably produce not tens of products in units of thousands, but thousands of products in units of tens.

\section{Case study 5: Fairwaves GSM base station}

Born at Moscow's Neuron Hackspace (neuronspace .ru/wp/), a startup named Fairwaves (fairwaves.co) is making a GSM (global system for mobile communications) base station (Figure 4; Table 5) that will enable $\$ 1 /$ month mobile phone subscriptions. The company's GSM network-in-the-box (NITB) base station costs $\$ 5000$ (vs millions of dollars for traditional equipment), has low power needs $(100 \mathrm{~W})$, and serves a $10 \mathrm{~km}$ radius.

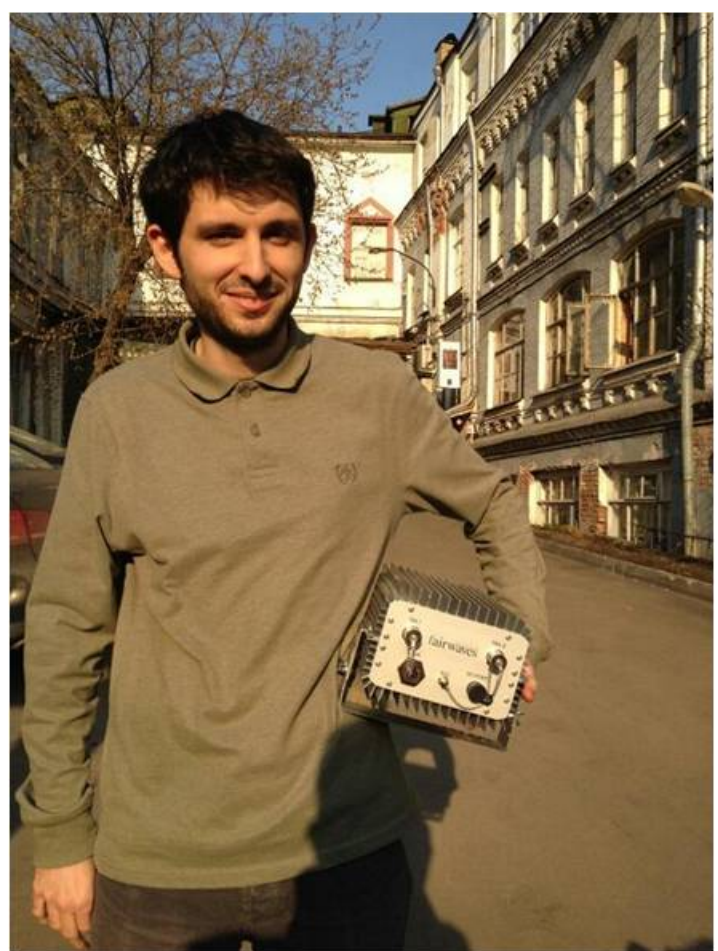

Figure 4. Fairwaves GSM base station

Source: Alexander Chemeris

Table 5. Case summary: Fairwaves GSM base station

\begin{tabular}{|c|c|}
\hline Dimension & Description \\
\hline $\begin{array}{l}\text { Novel product/service offering } \\
\text { (including target group) }\end{array}$ & $\begin{array}{l}\text { - GSM base station "in a box" for rural villages in developing economies and temporary } \\
\text { large gatherings in developed ones }\end{array}$ \\
\hline $\begin{array}{l}\text { Conventional offering with higher } \\
\text { complexity (including target group) }\end{array}$ & - Base station from Alcatel-Lucent, Ericsson, Motorola \\
\hline $\begin{array}{l}\text { Approach for reducing complexity } \\
\text { compared to conventional offering }\end{array}$ & $\begin{array}{l}\text { - In the company's own words, "In contrast to traditional mobile network solutions } \\
\text { that are highly centralized, dependent upon backhaul and making heavy use of this, } \\
\text { the Fairwaves solution is built upon a distributed VoIP core that benefits from local } \\
\text { switching and is resilient to network failure" (Fairwaves, 2015). }\end{array}$ \\
\hline Economic aspects & $\begin{array}{l}\text { - Conventional base station costs millions of dollars } \\
\text { - Enables } \$ 1 / \text { month mobile phone subscriptions } \\
\text { - Lower operating (power network) and maintenance costs }\end{array}$ \\
\hline Environmental aspects & $\begin{array}{l}\text { - Because the system is low-power and compact, it does not require large amounts of } \\
\text { energy, equipment, or new open space (e.g., clearing of trees) to establish } \\
\text { - Can be powered from off-grid energy sources such as solar }\end{array}$ \\
\hline Social aspects & $\begin{array}{l}\text { - Brings data and conductivity to people who would otherwise not have access or } \\
\text { would not be able to afford it } \\
\text { - In } 2011 \text {, the United Nations declared Internet access a basic human right (UN General } \\
\text { Assembly, 2011) }\end{array}$ \\
\hline
\end{tabular}




\title{
Corporate and Grassroot Frugal Innovation
}

\author{
Liza Wohlfart, Mark Bünger, Claus Lang-Koetz, and Frank Wagner
}

It uses the Osmocom (osmocom.org) GSM stack, an open source initiative developing free software for mobile telephony, from the handset to the network.

Fairwaves has already deployed several networks, including a private network at the Walk of the World festival in the Netherlands and a community network in the rural village of Yaviche, Mexico.

Building on the core base station technology, Fairwaves is now working to help entrepreneurs become a full service telecommunications company. In the company's own words:

"Fairwaves is a new kind of full-stack telecom vendor, tailored to serve mobile operators in low-income areas. You could be a company of just few guys to start a mobile operator. No special skills and no expensive engineers needed. We provide everything you need to build a mobile network which is profitable even at \$2/month revenue per user. It scales from a single site to a countrywide network, offers free calls and roaming inside global Fairwaves network and can be controlled from your laptop" (Fairwaves, 2014).

Case study 6: Burning Man Festival, Black Rock City Cities are arguably our largest technologies - being built constantly, lasting for centuries, rigidly planned, and yet unplannable. Can a city be an example of frugal innovation? Black Rock City, Nevada, in western United States might be exactly that (Figure 5):

"Black Rock City, Nevada is an ephemeral town that exists for only one week each year, during Burning Man, a radical arts festival. At its maximum occupancy, the town has about 60,000 citizens and a post office, an emergency services crew, a volunteer police department, roads, houses, bars, clubs, restaurants, and hundreds of art installations and participatory "theme camps". After a week, the city is completely disassembled - much of it burned - leaving the stark, white desert exactly as bare as it had been when the event started" (Wikitravel, 2016).

Black Rock City displays many of the simplicity and sustainability characteristics of frugal innovation (Table 6). First, it reduces the concept of a city to the bare minimum: streets and avenues are laid out as a clock face radiating from the centre, and in concentric circles with names in alphabetical order. Every camp is expected to bring in everything - even water - for its inhabitants to survive for the week, and to take out everything, even wastewater. The "Ten Principles" embody many "frugal" ideas, in particular "leave no trace". The city infrastructure (streetlights, art installations, and public facilities) is all removed by staff and volunteers after participants have left.

Another key principle of Burning Man is "no spectators," or "you are part of the art". In that sense, it embodies the frugal innovation idea that anyone can make the things they need to solve a problem, and that everyone has skills and abilities that can be helpful to others. Outside the festival, the Burners Without Borders organization (burnerswithoutborders.org) "promotes activities around the globe that support a community's inherent capacity to thrive by encouraging innovative approaches to disaster relief and grassroots initiatives that make a positive impact” (Burning Man, 2016).

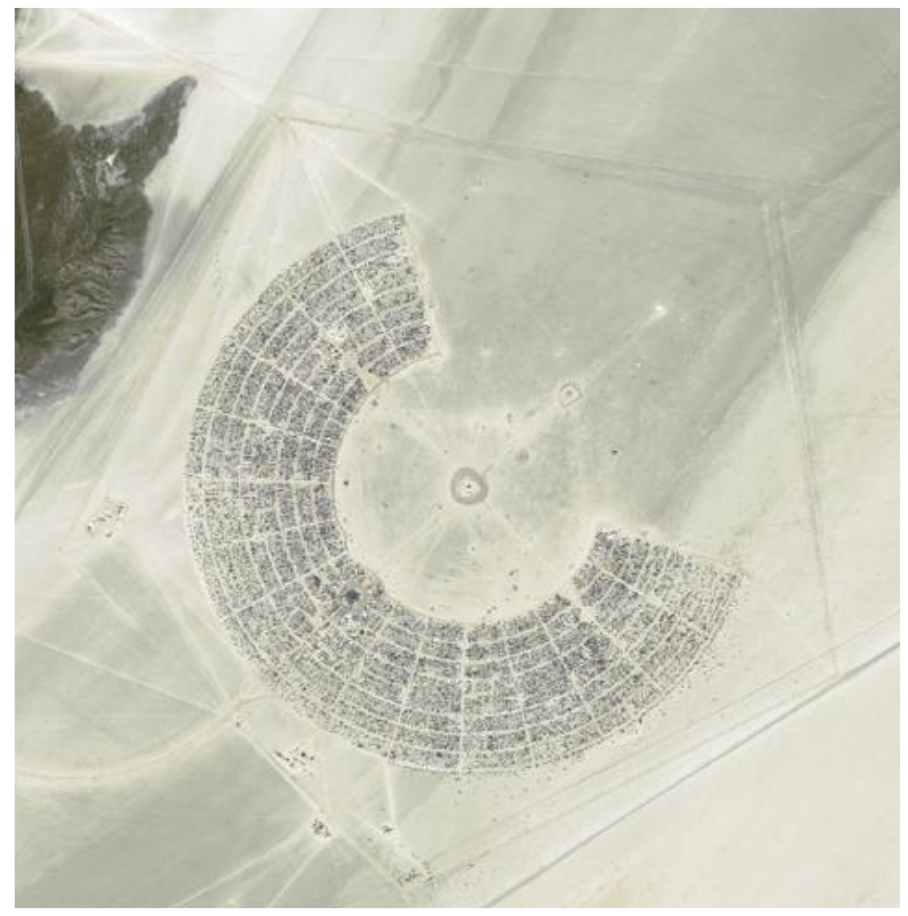

Figure 5. Satellite image of the Burning Man Festival in Black Rock City, 2005. Source: NASA

\section{Conclusion: Lessons Learned}

The case study analyses presented above highlight characteristics of corporate and grassroot frugal approaches. Considering the three pillars of sustainability has helped us to understand and contrast the cases. In conclusion, we offer a summary of key points and potential lessons to be learned between the two streams. 


\title{
Corporate and Grassroot Frugal Innovation
}

\author{
Liza Wohlfart, Mark Bünger, Claus Lang-Koetz, and Frank Wagner
}

Table 6. Case summary: Burning Man Festival, Black Rock City

\begin{tabular}{|c|c|}
\hline Dimension & Description \\
\hline $\begin{array}{l}\text { Novel product/service offering } \\
\text { (including target group) }\end{array}$ & $\begin{array}{l}\text { - A "pop-up" city of 70,000 people built for one week each year, and then completely } \\
\text { removed again }\end{array}$ \\
\hline $\begin{array}{l}\text { Conventional offering with higher } \\
\text { complexity (including target group) }\end{array}$ & $\begin{array}{l}\text { - Conventional cities are permanent structures built over centuries, obliterating the } \\
\text { natural environment. } \\
\text { - Festival sites offer little of the culture, comforts, and infrastructure of a city }\end{array}$ \\
\hline $\begin{array}{l}\text { Approach for reducing complexity } \\
\text { compared to conventional offering }\end{array}$ & $\begin{array}{l}\text { - Cultural rules such as "radical self-reliance" and "leave no trace" require each } \\
\text { participant to contribute, making for a modular and resilient physical and social } \\
\text { infrastructure }\end{array}$ \\
\hline Economic aspects & $\begin{array}{l}\text { - Participants pay ( } \$ 400 \text { ) for labour and materials that establish the city infrastructure } \\
\text { and remove it after use } \\
\text { - Larger features of the city are art projects, sponsored by artists backers or given freely } \\
\text { - Each camp is a self-contained supply chain, responsible for its own power, food, } \\
\text { water, and even trash disposal }\end{array}$ \\
\hline Environmental aspects & $\begin{array}{l}\text { - All water and food is brought in by each participant, and each participant must leave } \\
\text { their camp empty of trash } \\
\text { - No plants or animals are allowed, in case they would disturb the austere desert } \\
\text { ecology; even pouring wastewater onto the ground is prohibited } \\
\text { - Considerable work goes into professional and volunteer cleanup after the event. }\end{array}$ \\
\hline Social aspects & $\begin{array}{l}\text { - Participants ("burners") strive to apply festival principles in everyday life } \\
\text { - Burners Without Borders organization runs social benefit projects based on principles } \\
\text { and solutions developed for the festival }\end{array}$ \\
\hline
\end{tabular}

Comparing corporate and grassroot frugal approaches First, findings presented in this article highlight the specifics of corporate and grassroot frugal solutions, including areas of overlap (Table 7). Both innovation streams set a clear focus on a specific price-sensitive customer group and restrict the features of the solution to its core needs. This focus may entail features that even go beyond the current status if these are considered a necessity from the customers' point of view. All frugal solutions have a comparatively low price compared to high-end solutions. And, they have a profitable business model with varying definitions of profitability from a company and an inventor's perspective.

The differences between corporate and grassroot frugal innovations result from their origins and ultimate goals (Table 8). Corporate frugal solutions are driven by companies that have identified a profitable market opportunity. They use an elaborate development process (and dedicated R\&D teams) to carefully design a mass- producible solution. Economies of scale help to achieve a high economic sustainability despite small profit margins. A good understanding of their target customers' needs is the key success factor of corporate frugal solutions. Challenges include the cannibalization of the company's existing high-end offering and damages to its brand if the frugal offering does not match its quality.

Grassroot frugal innovations are driven by individual inventors, who are part of or close to the target group. They start the development of the frugal offering because they perceive a problem faced by this group and have a clever idea how to solve it. Their solution has to meet the needs of this group but not a certain quality standard, and it does not have to make a lot of profit social and environmental aims come first. They have to rely on restricted resources to develop single items or small series and usually do not use specific methods for it but an improvised process with many prototypes designed and re-designed in trial-and-error loops. Collab- 


\section{Corporate and Grassroot Frugal Innovation}

\section{Liza Wohlfart, Mark Bünger, Claus Lang-Koetz, and Frank Wagner}

Table 7. Overlaps in corporate versus grassroot frugal innovation

\begin{tabular}{lc}
\hline Category & Corporate Frugal \\
\hline Target customers & Clearly defined price-sensitive customer group \\
\hline Features & Restriction of solution features to core needs of target customers \\
\hline Price & Comparatively low price compared to high-end solutions \\
\hline Business model & Profitable business model \\
\hline Sustainability focus & Sustainability mentioned as a general motivation but with different focus (see Table 8) \\
\hline
\end{tabular}

Table 8. Differences between corporate versus grassroot frugal innovation

\begin{tabular}{|c|c|c|}
\hline Category & Corporate Frugal & Grassroot Frugal \\
\hline Driver & Companies & $\begin{array}{l}\text { Individual inventors, who are part of or close to } \\
\text { the target group }\end{array}$ \\
\hline Impulse & Market opportunity & Clever idea to solve a problem \\
\hline \multicolumn{3}{|l|}{ Sustainability } \\
\hline Economic & Primary motivation, high profitability targeted & $\begin{array}{l}\text { Secondary motivation, low economic profitability } \\
\text { accepted }\end{array}$ \\
\hline Environmental & Secondary motivation & Secondary motivation \\
\hline Social & Secondary motivation & Primary motivation \\
\hline Quality & In line with brand & Good enough for target customers \\
\hline Production scale & Mass-manufacturing & Single items and small series \\
\hline \multirow[t]{3}{*}{ Development process } & Complex, resource-intensive & Simple, resource-restricted \\
\hline & Structured, method-based & Improvised \\
\hline & Elaborate prototypes & Early, fast, frequent prototyping \\
\hline Success factors & $\begin{array}{l}\text { (Dedicated) corporate R\&D teams, close } \\
\text { collaboration with customers }\end{array}$ & $\begin{array}{l}\text { Input from other designers, collaborative/crowd } \\
\text { design }\end{array}$ \\
\hline Challenges & $\begin{array}{l}\text { Cannibalization of existing offering, brand } \\
\text { damages }\end{array}$ & Upscaling \\
\hline
\end{tabular}




\title{
Corporate and Grassroot Frugal Innovation
}

\author{
Liza Wohlfart, Mark Bünger, Claus Lang-Koetz, and Frank Wagner
}

oration with other designers, for example through crowd-based approaches, is key to their success; their main challenge is upscaling.

In the case studies presented here, sustainability was mentioned as the main objective for developing and implementing the frugal solution. In many of the cases, positive environmental or social impacts were obtained and are actively promoted when communicating to customers and the general public, while the main goal of their products or solutions was to gain a competitive advantage and make profit.

In most cases, to achieve a sustainable product in the full sense was not a main strategic goal when initiating the innovation process. The corporate frugal cases primarily focused on economic sustainability; the grassroot cases focused on social sustainability. Environmental sustainability seems to be more of a side-effect than an upfront impulse for frugal initiatives. Especially from the corporate perspective, frugal innovation principles are applied to achieve a high profitability and thus contribute mainly to economic sustainability.

Common to all approaches is a need to rethink conventional assumptions about materials, processes, and designs in order to do more with less, and in the process, to exceed current expectations of value creation.

\section{Sustainability as a general lever for and benefit of frugal innovations}

In general, the requirement for applying a "resourceconstraint" product development approach leads to the hypothesis that frugal innovations provide the potential of contributing to more sustainable products with a smaller ecological footprint than usual. Given that frugal innovations are (by definition) more affordable than conventional solutions, they can also be used by a broader part of society and hence a positive social impact is often seen. Some solutions explicitly target social objectives, for example by supplying affordable technologies to provide clean drinking water or offer solar cooking stoves. Thus, they offer people with a low income access to life-improving technologies (see Basu et al., 2013; Brem \& Ivens, 2013; Jänicke, 2014; Schrader, 2011; Prahalad, 2010).

Possible indirect effects, however, have to be considered taking all three pillars of sustainability into account. For instance, frugal innovations could be attractive for existing customers of high-price products from the same company and reduce their sales volume (i,e., cannibalization). Also, if more people can afford the now more affordable products with reduced functionalities, the total number of products would rise and thus overall material and energy use would increase (i.e., the rebound effect).

A holistic assessment of products and services can be supported by lifecycle thinking. This perspective looks at the whole process chain from "cradle" (i.e., extraction of raw materials) over manufacturing of intermediary and final products and the use phase to "grave" (i.e., end-of-life, disposal, recycling). Lifecycle assessment is the most common method and can be used to assess environmental and social aspects (see ISO 14040, 2006; Weidema, 2004). However, such detailed studies about the sustainability impact of frugal innovations have so far not been conducted. It would be interesting, for example, to take a closer look at the possibility to dismantle or refurbish grassroot frugal innovations, given that this aspect will have a strong impact on the related waste. The distributed production of many grassroot frugal innovations is a benefit to be taken into account, especially given that the transport distances involved in the global supply chains of high-end products often have a significant environmental impact.

\section{Lessons learned between the two frugal streams}

Our case study analyses suggests that the different frugal streams can profit from each other in some way. The resource-constrained development processes of grassroot frugal innovators can teach companies how to radically re-think innovation. Methods and tools from both approaches can be valuable.

Industrial companies use elaborate development processes supported by methods such as value curves and morphological boxes in order to obtain deep understanding of the specific requirements of target customers' needs and translate them into suitable concepts. Some of those methods offer very hands-on practical support that can also be very helpful for grassroot frugal startups. Know-how transfer could be done, for example, by mentoring programs or seminars offered by chambers of industry and commerce or regional economic development organizations.

Grassroot frugal entrepreneurs also often struggle to scale up manufacturing of their solutions because the products were not initially designed to be mass manufactured, and the inventors often do not have access to manufacturing assets. Corporate know-how can help 


\title{
Corporate and Grassroot Frugal Innovation
}

\author{
Liza Wohlfart, Mark Bünger, Claus Lang-Koetz, and Frank Wagner
}

them to make their concepts profitable on a large scale. A more recent means for the inventors to access these skills are "maker movement" accelerators (e.g., Dragon Innovation or Lemnos Labs), which teach these skills to inventors.

Grassroot frugal approaches are often based on personal experiences and problems of inventors and entrepreneurs, who come up with ideas on how to improve everyday life with a new product or solution. People involved in grassroot frugal innovations usually have a strong entrepreneurial spirit that enables them to come up with radically new product or service ideas and to successfully re-think the traditional way business models work. Industrial companies can simulate this atti-

\section{About the Authors}

Liza Wohlfart (MA) works as a Scientist and Project Manager at the Competence Center R\&D Management of Fraunhofer IAO in Stuttgart, Germany. She has longterm experience with national and international research and consulting projects. Topics of specific expertise include innovation management, business development, frugal innovation, and the human side of $R \& D$. She has been the manager of large international projects, both EU- and industry-funded, where she has been responsible for the development of Community of Interests among Russian SMEs and the establishment of an Innovation Audit Tool for South-Australian SMEs. She is the editor of two books on knowledge management and business development, and she is the author of several scientific publications. She has delivered seminars and intermediary training sessions related to innovation as well as lectures on project management. Her international experience includes several European countries as well as Brazil, Russia, Australia, and Malaysia.

Mark Bünger is Vice President of Research at Lux Research. Since joining Lux in 2005, Mark Bünger has seeded, launched, and led many of the company's intelligence services and consulting work, ranging from bio-based fuels and chemicals to big data in agriculture and healthcare. Mark previously worked at Forrester Research, Accenture, and several successful startups. His business education at Mälardalen Polytechnic (Sweden) and the University of Texas (United States) focused on market research, complemented by studies and lab work in neurology and bioengineering at the University of California (Berkeley and UCSF). He is a standing guest lecturer at UC Berkeley and collaborates tude by collaborations with frugal startups or new organizational forms such as corporate startups.

Other potential approaches for enhancing a grassroot mentality include setting up dedicated R\&D teams that are located in the country targeted by frugal solutions. Being close to the end user helps innovators to come up with simplified technical approaches that perfectly match user requirements.

Applying additional methods is also a potential way forward. Tools such as design thinking leverage the idea of (bottom-up) DIY approaches to tightly include customers in (top-down) design processes of industrial companies.

widely on studies of innovation with Fraunhofer Institute (Germany), LUMS (Pakistan), Masdar (Abu Dhabi), and the Moscow State University of Mechanical Engineering, among others.

Claus Lang-Koetz is Professor for Sustainable Technology and Innovation Management at Pforzheim University in Pforzheim near Stuttgart, Germany. His research interests are management methods and tools that help companies to deal with innovation ideas and implement them into resource efficient products and solutions - while using new technologies where appropriate.Claus studied Environmental Engineering (Dipl.-Ing.) and Water Resources Engineering and Management (MSc) in Germany and the United States. He worked in applied research at University of Stuttgart and Fraunhofer Institute for Industrial Engineering from 2000 until 2009 and obtained a doctorate in Engineering Science (Dr.-Ing.) at the University of Stuttgart in 2006. From 2009 through 2014, he was Head of Innovation Management at Eisenmann SE, a plant engineering and equipment firm supplying, for example, systems for surface finishing technology worldwide.

Frank Wagner is Head of the Competence Centre R\&D Management at Fraunhofer IAO and a lecturer in Technology Management at the University of Stuttgart, Germany. Based in Brisbane, Australia, as a Professor at Queensland University of Technology (QUT), Frank is working on R\&D and innovation projects mostly relating to the Innovation Manufacturing CRC and Assistive Technologies. He has over two decades of experience in implementing numerous innovation and technology management, corporate development, and organizational design projects across various sectors in Australia, Asia, America, and Europe. 


\section{Corporate and Grassroot Frugal Innovation}

\section{Liza Wohlfart, Mark Bünger, Claus Lang-Koetz, and Frank Wagner}

\section{References}

Brem, A., \& Ivens, B. 2013. Do Frugal and Reverse Innovation Foster Sustainability? Introduction of a Conceptual Framework. Journal of Technology Management for Growing Economies, 4(2): 31-50.

Burning Man. 2016. Burners Without Borders. BurningMan.org. Accessed April 1, 2016:

http://burningman.org/culture/civic-programs/burners-withoutborders/

Fairwaves. 2014. Fairwaves: Bringing Mobile Communication to the Next Billion. Venture Capital for Africa. Accessed April 1, 2016: https://vc4a.com/ventures/fairwaves/

Fairwaves. 2015. Our Solution: Profitable Networks Anywhere. Fairwaves.com. Accessed April 1, 2016: https://fairwaves.co/our-solution/

Fraunhofer IAO. 2014. Low-Cost Innovation. Frugale Innovationen als Weg zur Erschließung kostensensitiver Märkte. Presented at Fraunhofer IAO seminar: Low-Cost Innovation. Frugale Innovationen als Weg zur Erschließung kostensensitiver Märkte, November 12 .

Fraunhofer IAO. 2012. Wenn weniger mehr ist. Durch Low Cost Innovationen neue Kundengruppen gewinnen. Seminar. 28 June 2012.

Glemser, D. 2013. Low-Cost Innovationen: Charakteristika und Erfolgsfaktoren. Master's thesis at the University of Stuttgart, Institute for Work Science IAT.

Grallert, A. 2014. Konsequentes Innovationsmanagement durch Strategiewechsel: Eine Hotelmarke erfindet sich neu. Presented at Fraunhofer IAO seminar: Low-Cost Innovation. Frugale Innovationen als Weg zur Erschließung kostensensitiver Märkte, November 12 .
ISO 14040. 2006. Environmental Management - Life Cycle Assessment - Principles and Framework. Berlin: Beuth Verlag.

Jänicke, M. 2014. Frugale Technik. Ökologisches Wirtschaften, 29(1): 30-36.

http://dx.doi.org/10.14512/OEW290130

Prahalad, C. K. 2010. The Fortune at the Bottom of the Pyramid. New Jersey: Wharton School Publishing.

Schrader, C. 2011. Beiträge multinationaler Unternehmen zur nachhaltigen Entwicklung in Base of the Pyramid-Märkten. In J. Freimann (Ed.), Schriften zur Nachhaltigen Unternehmensentwicklung. Munich: Rainer Hampp Verlag.

Strotz, M. 2014. Low Cost Innovations. R\&D in China - Lessons Learned. Presented at Fraunhofer IAO seminar: Low-Cost Innovation. Frugale Innovationen als Weg zur Erschließung kostensensitiver Märkte, November 12.

UN General Assembly. 2011. Report of the Special Rapporteur on the Promotion and Protection of the Right to Freedom of Opinion and Expression. New York: United Nations General Assembly.

Weidema, B. P. 2004. The Integration of Economic and Social Aspects in Life Cycle Impact Assessment. The International Journal of Life Cycle Assessment, 11(Suppl. 1): 89-96. http://dx.doi.org/10.1065/lca2006.04.016

Wikitravel. 2016. Black Rock City. Wikitravel.org. Accessed April 1, 2016: http://wikitravel.org/en/Black_Rock_City

Zeschky, M., Wiedenmayer, B., \& Gassmann, O. 2011. Frugal Innovation in Emerging Markets. Research Technology Management, 54(4): 38-45. http://dx.doi.org/10.5437/08956308X5404007

Citation: Wohlfart, L., Bünger, M., Lang-Koetz, C., \& Wagner, F. 2016. Corporate and Grassroot Frugal Innovation: A Comparison of Top-Down and Bottom-Up Strategies. Technology Innovation Management Review, 6(4): 5-17. http://timreview.ca/article/977

Keywords: frugal innovation, sustainability, corporate frugal innovation, grassroots frugal innovation, case studies, startups 